\title{
TRANSEXUALIDADE E EDUCAÇÃO: UTILIZAÇÃO DO NOME SOCIAL COMO FORMA DE INCLUSÃO NO ESTADO DO CEARÁ
}

Tiago Alves Callou'; Maria Eduarda Henrique Mascarenhas ${ }^{2}$; Priscila Ribeiro Diniz ${ }^{3}$

Resumo: O nome é utilizado para identificar, diferenciar e individualizar o ser humano, para que tenha um convívio interpessoal e inclusão social. No entanto, quando se aborda a temática da transgeneridade surge uma incompatibilidade do nome do registro civil com a expressão de gênero da travesti e da/do transexual. Para solucionar essa questão, faz necessário a utilização do nome social, mas este não é regulamentado em todos os estados federativos do Brasil. A pesquisa teve como objetivo geral analisar a utilização do nome social como forma de inclusão das travestis e das/dos transexuais, bem como as legislações brasileiras pertinentes a temática. A metodologia utilizada para desenvolver o trabalho foi à pesquisa bibliográfica, pois se utilizou de manuais e legislações pátrias, e o método dedutivo para obter uma conclusão da temática. Como conclusão, percebeu-se que mesmo com algumas normas possibilitando a utilização do nome social, ainda é necessário que o ordenamento jurídico progrida na direção de uma maior igualdade e acessibilidade de direitos.

Palavras-chave: Educação. Nome Social. Transgêneridade.
Abstract: The nameis utilized to identify, diferenciate and individualize thehumanbeing, in ordertocoexistinterpersonallyand cause a social inclusion. However, when approaches the the meoftransgender, rise a incompability ofthename in the civil's

\footnotetext{
${ }^{1}$ Mestrando em Ciências das Religiões pela Universidade Federal da Paraíba-UFPB; Especialista em Processo Civil pela Universidade Regional do Cariri-URCA; Bacharel em Direito pela Faculdade Paraíso do Ceará-FAPCE; Integrante do Grupo de Estudos em Gênero, Geração e Direito FAP; Advogado.

${ }^{2}$ Graduanda em Direito pela Faculdade Paraíso do Ceará-FAPCE. Integrante do Grupo de Gênero, Geração e Direito FAP

${ }^{3}$ Docente na Faculdade Paraíso do Ceará-FAPCE. Doutoranda em Ciências das Religiões pela Universidade Federal da Paraíba-UFPB. Mestre em Sociologia pela Universidade Federal da Paraíba-UFPB. Bacharel em Ciências Sociais pela Universidade Regional do Cariri-URCA. Coordenadora do Grupo de Estudos em Gênero, Geração e Direito FAP.
} 
registration with the expressio noftra vestite or transsexual. To solve thisquestion, it does necessary the utilization ofthesocial's name, butit's still notregulated in every federal states of Brazil. The researchhad the objective to analise theutilization of social's name as a way to inclusion of travestites and transsexuals, as well as the brazilian legislation pertinent to this thematic. The method utilized to develop this article was bibliography's research, because wa utilized manuals andhomeland'slegislation, and the dectutive's methodtoobtain a conclusion ofthethematic. As conclusion, it was noticedthatevenwith some rules making possible the utilizationofsocial'sname, is still necessary that thelegal'sregulation advance in the direction that can reach a great ere quality and accessibili tyo frights.

Keywords: Education. Social Name. Transgendered.

\section{Apresentação}

As/Os travestis e transexuais possuem direitos e garantias como todos os outros cidadãos e cidadãs do Estado
Democrático de Direito, no entanto, eles são discriminalizados e lançados à margem da sociedade, necessitando de proteção estatal; pois os traços transgêneros são vistos como fatores descaracterizantes "do ser de direitos".

O presente artigo apontará os problemas e as soluções cabíveis para a inclusão do grupo transgênero no meio social educacional. Nesse tocante basta observar o aumento do preconceito, crimes de ódio por parte da sociedade heteronormativa, mergulhada no conservadorismo e na padronização sexual. A desconstrução e a retirada do binarismo seria um dos principais objetivos, contudo a questão jurídica como ter os mesmos direitos que um casal hétero causa sensação desigualdade, diferenciação por sua identidade de gênero e/ou opção sexual. Identificá-los (as travestis e os/as transexuais) como sujeitos de direitos inerentes a sua identidade de gênero e/ou opção sexual.

Assim, a metodologia do texto foi baseada em pesquisas bibliográficas tendo como alicerce os entendimentos de gênero de Judith Butler (2003) e também da redação constitucional de 1988 que dispõe teoricamente igualdade entre os indivíduos, supondo também seus 
deveres e direitos, e é a partir desses direitos que se chegará ao respeito, a alteridade.

No presente trabalho, se discute a possibilidade da utilização do nome social nos registros internos das instituições escolares, bem como o tratamento por via oral pelo nome social dos/das estudantes travestis e transexuais (o nome social já é utilizado por essa parte da população, principalmente pelo Sistema Único de Saúde - SUS, no qual já consta nos seus cadastros o campo para inclusão do nome social). Para isso, foi utilizado a pesquisa bibliográfica e o método dedutivo. Bibliográfica pois utilizou-se de documentos escritos e de doutrinas para realizar a fundamentação da pesquisa, e dedutivo, pois a partir de linhas lógicas e racionais pode-se chegar a uma conclusão sobre a temática abordada.

A utilização do nome social é meio de inclusão da população trans, seja travesti ou transexual, acarretando na diminuição do constrangimento durante os questionamentos: Por que o nome civil não corresponde a expressão de gênero desse indivíduo; entre outras.

Das Formas De Expressão De Gênero E Sexualidade
No âmbito social somos ensinados a apenas aceitar o binarismo de seres no aspecto biológico (entre homem/macho e mulher/fêmea, excluindo os intersexos que não se identificam com nenhum dos sexos), no qual, se engloba a binariedade de gênero/sexo, ou seja, crer que somente é "normal" a sociedade composta pelo homem e pela mulher e existe nela uma relação de poder (ao acreditar na heterossexualidade como padrão, a sociedade força o individuo a torna-se hétero), a qual justifica a segregação dos outros gêneros, pois é moralmente imposto pelo social. Biologicamente a partir do momento que é descoberto o sexo (na quantidade de cromossomos e/ou no formato da genitália), se espera que o sujeito apresente as características esperadas para com o seu órgão genital. O corpo passa a ser objeto passível de interpretações sob o aspecto binário e genérico, o qual ganha significado sexual. Tendo em vista que o sexo é biológico, ou seja, uma distinção feita pelo que conseguem ver e distinguir um ser de outro, a definição do gênero limitada ao sexo aparente, o gênero é construído socialmente e/ou culturalmente, isto é, formado a partir de 
aspectos sociais (da forma de si identificar e ser identificado como homem ou mulher), abrindo espaço para a construção do sexo a partir da interpretação do que é gênero. (BUTTLER, 2003)

Percebe-se a incompatibilidade dos termos, dai surgir à discussão sobre identidade de gênero, no qual saímos do binarismo (hierarquizado, não há igualdade nos vínculos estabelecidos entre homem e mulher), segundo Butler (2003, p. 24) “[...] o gênero reflete o sexo ou é restrito por ele.". Dai entramos na multiplicidade, onde existe a quebra de conceitos, quando falamos sobre identidade de gênero (entendemos como algo subjetivo) logo se faz uma ligação à orientação sexual, contudo esses termos têm significados diferentes, o primeiro é o gênero com o qual o individuo se identifica, podendo ou não concordar com o sexo biológico e o segundo é o desejo, a atração afetivossexual por alguém de determinado gênero.

A Constituição Brasileira de 1988 em seu preâmbulo apresenta o objetivo do texto constitucional “[...] destinado a assegurar o exercício dos direitos sociais e individuais, a liberdade, a segurança, o bem-estar, o desenvolvimento, a igualdade [...]", então vemos que "formalmente teríamos certa igualdade e garantia de direitos", mas não há efetivação de fato, pois colocam em um plano maior a orientação sexual e a identidade de gênero do que a pessoa em si. O indivíduo tem o seu gênero posto após o seu nascimento, passa a se comportar dentro dos padrões estabelecidos por sua comunidade/Estado, em consequência o Estado passa a oprimir aqueles que não se encaixam nessas categorias e seguindo essas normas a sociedade permanece no conservadorismo, fixando mais uma vez o modelo heteronormativo. Conforme Butler (2003, p. 38) expõe: "Gêneros inteligíveis" são aqueles que, em certo sentido, instituem e mantêm relações de coerência e continuidade entre sexo, gênero, pratica sexual e desejo.", a comunidade/Estado espera essa padronização.

Atualmente vemos esses grupos esmagarem as minorias (os homossexuais, transexuais, entre outros) e usarem para aumentar a discriminação argumentos moralistas, a religião (principalmente a católica que tem uma atuação muito forte, pois reforça o conceito de binariedade e o preconceito com as pessoas de orientação diferente 
do que se esperava, ligando a esta o conceito de pecado), é evidente, por exemplo: "a bancada da Bíblia" não aceita certas decisões para a comunidade LGBTTQIA (Lésbicas, Gays, Bissexuais, Travestis, Transexuais, Queer, Intersexuais, Assexuais) e assim os direitos dessas pessoas ficam restringidos por conta da concepção religiosa do que é pecado, certo ou errado, o que não deveria acontecer, pois rompe justamente entre o bem da coletividade e os interesses privados de determinado grupo.

O que essa bancada propõe é a defesa da família tradicional brasileira, como colocada na Bíblia (com Adão e Eva), essa posição se torna contraditória aos princípios fundamentais (como o princípio do pluralismo político que considera que todos possam exercer seus direitos sem ferir os direitos do próximo, participar da vida política em função dos seus direitos, com objetivo de representar todos, inclusive as minorias, respeitar as diferenças e no qual está intimamente ligado com o princípio da dignidade humana), aos direitos (de liberdade, livre desenvolvimento da personalidade, privacidade, proteção à dignidade humana e saúde) e garantias fundamentais inseridos na Constituição de 1988, expressa em seu artigo $3^{\circ}$, inciso IV, artigo $5^{\circ}$, incisos VIII e X.

A teoria da performatividade (na qual o gênero se manifesta como consequência cultural e social), adotada por Judith Butler (1998), que está inserida dentro da Teoria Queer (a qual se caracteriza pela desconstrução do sujeito, fugindo dos padrões, estudando os gêneros que não foram normalizados pela sociedade, por exemplo, a trevestilidade) e que também estuda como a ação histórica-social restringe o conhecimento sobre a identidade do ser. A comunidade LGBTTQIA enfrenta a exclusão dos grupos sociais, a discriminação, o preconceito, a rejeição por ser diferente (socialmente são considerados "anormais") e por esses fatos são marginalizados, pois não existe o sentimento de alteridade entre as pessoas e pelo fato de terem uma identidade de gênero/orientação sexual diferente, a condição de pessoa e a sensibilidade são retiradas pelos preconceituosos, e isso converte-se em uma certa proibição do exercício de seus direitos, por exemplo de constituir família nos parâmetros da lei.

O ponto a ser desenvolvido no artigo será sobre a Transexualidade, não excluindo a importância de debater os 
grupos de gêneros diversos, colocando como foco a questão da educação. Essa marginalização fica explicita quando os índices de homicídio, a prostituição, as desistências nas instituições educacionais de ensino médio e superior, os obstáculos em conseguir um emprego, a rejeição familiar, os crimes de ódio crescem em virtude da discriminação.

\section{Diferenciações Dentro Dos Grupos Transgêneros}

O guarda-chuva $\mathrm{T}$ e sua pluralidade (expressão usada para designarem-se aos Transexuais, Travestis), o enfoque maior será em torno dos/das transexuais e das travestis é fundamental saber a diferença entre os dois grupos, o primeiro se caracteriza pela não aceitação do gênero atribuído no nascimento, antes marcados pela realização da cirurgia de redesignação genital/sexual ou de transgenitalização (popularmente conhecida como a mudança de sexo) e atualmente não necessitam mais da cirurgia para terem o reconhecimento de sua identidade, porém o órgão lhe traz repulsa; e o segundo grupo, como coloca $\operatorname{Barbosa}(2010$, p. 9): "[...] as travestis se vestem e vivem o gênero oposto, enquanto a transexual se sente no gênero oposto. [...] para as travestis faria sentido falar que elas buscam o gênero oposto, porque as travestis não abandonam o gênero masculino".

A identidade transgênero não se vincula somente ao corpo, a uma ligação de corpo e mente, e a toda uma transformação de seu gênero (retirando a sexualidade como o pensamento de que só possam existir homens e mulheres no sentido biológico, não restringindo essas pessoas a dicotomia havendo a desnaturalização do gênero). Dependendo do gênero que adota e do gênero com o qual sente atração, o transgênero pode identificar-se como bissexual, heterossexual, homossexual: sente atração pelos dois gêneros, sente atração por pessoa do gênero oposto, sente atração por pessoa do mesmo gênero.

Ao que cabe e está relacionado aos transexuais a ADI (Ação Direta de Inconstitucionalidade) $\quad \mathrm{n}^{\circ} 4 . \quad 725$, protocolada no dia 03, de junho, de 2011 pelo Ministro Marco Aurélio, na qual dispõe sobre os direitos do/da transexual em relação à mudança do nome e do sexo (masculino/feminino) no Registro Civil sem ter realizado a cirurgia redesignação genital. Como disposto: Art. $5^{\circ}[. ..] \mathrm{X}$ - são 
invioláveis a intimidade, a vida privada, a honra e a imagem das pessoas, assegurado o direito á indenização pelo dano material ou moral decorrente de sua violação.

A questão explicada pelo Ministro seria que ao mostrar o documento o homem ou a mulher transexual passaria pelo constrangimento de explicar a situação do seu documento não condizer com a realidade física, causando transtornos psicológicos, emocionais, afastando-o de ambientes onde terá de passar por casos semelhantes. Diante disso, é importante estabelecer critérios para a inclusão dessas pessoas no meio social de forma tal, a serem reconhecidos da maneira como se sentem.

Outra questão vinda a juízo é a inclusão de homens e mulheres transexuais na tabela SIH-SUS para o recebimento de remédios antes da cirurgia de transgenitalização e outros procedimentos, pois como vem colocado na APELAÇÃO CÍVEL N $\mathrm{N}^{\circ}$ 2001.71.00.026279-9/RS a sua exclusão gera situações desconfortáveis e instiga a discriminação as pessoas transexuais pelo fato de não exercer seus direitos de liberdade, livre desenvolvimento da personalidade, além de ofender o princípio da igualdade e a dignidade da pessoa humana (o ser humano como um fim em si mesmo), um dos mais valorosos princípios interiorizados pela Constituição vigente, se usa da sexualidade para definir de fato os indivíduos, no texto o relator. Roger Raupp Rios (Juiz Federal) claramente justifica sua posição ao colocar os/as transexuais como sujeitos de direitos não mais como objetos, e mais não deve ser interferido por terceiros sua liberdade sexual. A problemática se desenvolve em torno do direito a saúde, como disposto:

Art. 196. A saúde é direito de todos e dever do Estado, garantido mediante políticas sociais e econômicas que visem à redução do risco de doença e de outros agravos e ao acesso universal e igualitário às ações e serviços para sua promoção, proteção e recuperação.

O qual se estende a todos (com efeito, erga omnes) sem qualquer distinção, e a necessidade do SUS cobrir os procedimentos médicos possíveis para a garantia de uma saúde física e mental melhor. A União em sua defesa nega haver discriminação, porém em contra partido menciona que não existe necessidade da realização da cirurgia por 
se tratar de uma "doença" (referindo-se aos transexuais), aqui, sem dúvida, demonstra o pensamento retrógrado e coberto de preconceitos.

É concebendo direitos as minorias que se consegue uma comunidade igualitária e harmoniosa, a mudança de nome é só um dos direitos que podem se garantidos a eles (os transgêneros, e a toda classe LGBTTQIA). Como coloca SCOTT (1989) gênero é apenas uma classificação gramatical, todos devem ser tratados como iguais.

\section{Do Nome Civil E Nome Social}

O código civil de 2002, no capítulo dos direitos da personalidade, aborda a temática do nome, e no seu artigo 16 dispõe que "toda pessoa tem direito ao nome, nele compreendidos o prenome e o sobrenome", englobando assim, todos os indivíduos do Estado brasileiro sem distinção.

O codex civilista não faz ressalvas nem restrições de quem pode ou não pode se utilizar desse direito personalíssimo. No artigo 19 do mesmo código expressa que “o pseudônimo adotado para atividades lícitas goza da proteção que se dá ao nome", ou seja, essa proteção e garantia a utilização ao nome também se estende ao pseudônimo utilizado por artistas, escritores entre outros.

Tartuce (p.104, 2012) explica que “apesar da falta de previsão, deve-se concluir que a proteção constante no art. 19 do Código Civil atinge também o cognome ou alcunha, nome artístico utilizado por alguém, mesmo não constando esse no registro da pessoa". Dessa forma, a proteção ao nome ultrapassa o conceito restrito constante no registro civil do indivíduo, passando a proteger também o nome que ele utiliza, se reconhece e é reconhecido socialmente.

O nome utilizado pelo indivíduo o identifica, diferencia e individualiza no meio social, sendo de suma importância a sua utilização e proteção, ressaltando que o mesmo não pode gerar desconforto ou abalo psicológico a quem o utiliza. Nessa linha de pensamento, Próchno e Rocha (p.255, 2011) explicam que:

O nome, segundo o referencial jurídico, aparece como uma categoria classificatória significativa em nossa sociedade. Por meio dele, é referendada a existência do indivíduo perante $\mathrm{o}$ Estado $\mathrm{e}$ as instituições públicas, sendo a certidão de nascimento $\mathrm{e} o$ 
documento de identidade meios que conferem a legitimidade para o exercício da cidadania.

A partir do nascimento ou mesmo no período gestacional o nome acompanha o ser humano, sendo um dos primeiros direitos inerentes atribuídos a ele, bem como o direito à vida, à integridade física e moral, entre outros. Neste momento, Já é designado junto com o nome, as relações de sexualidade e gênero, ou seja, se o sexo biológico for masculino, o nome da criança tem que ser masculino, e se o sexo biológico for feminino, o nome tem que ser feminino.

Além da identificação, diferenciação e individualização, o nome também carrega padrões socioculturais que deverão ser seguidos pelo indivíduo. Conforme Humildes (2007) apud Próchno e Rocha (p.255, 2011):

(...) a sociedade delimita papéis relativos ao gênero tomando como ponto de partida o sexo jurídico, indicado pela natureza biológica e referenciado pelo prenome, para daí construir um suposto sexo social que, por sua vez, decorre de uma educação familiar e social recebida pela criança de acordo com seu sexo jurídico. No que tange ao papel sexual, há uma expectativa do grupo para que o indivíduo atue em conformidade com as linhas traçadas para o papel de homem e de mulher, preconizando-se, assim, um protótipo de normalidade heterossexual na sociedade ocidental. Ou seja, essa mesma sociedade, através de sua história, constrói uma figura rígida de homem ou mulher e força os indivíduos que dela participam a uma conduta estrita às normas estabelecidas.

Como verificado, o nome trás consigo muitas informações e padrões a serem seguidos. Nesse aspecto, adentrase na temática da transexualidade e de todo o conceito "guarda-chuva T", seja transexual, transgênero, travesti, entre outros. Para essa parte da população, o nome que consta no seu registro de nascimento pode gerar um desconforto, pois este não corresponde a sua expressão de gênero, e como já mencionado anteriormente, o nome utilizado também manifesta relações de sexualidade e gênero.

Desse embate e não correspondência entre o nome e a expressão de gênero, surge o nome social, que conforme o Decreto $\mathrm{N}^{\circ} 8.727$ de 28 de abril de 2016 no seu artigo $1^{\circ}$, I, é “designação pela qual a pessoa travesti ou transexual se identifica e é socialmente reconhecida". Ou seja, é a palavra, seja ela simples ou composta, utilizada pelo ou pela transgênero para 
ser identificada, diferenciada e individualizada no meio social, correspondendo com sua expressão de gênero. O nome social acarreta em um conforto maior na identificação do indivíduo, seja por ele mesmo ou por terceiro, diminuindo o constrangimento da utilização do nome que consta no registro de nascimento.

Para exemplificar, utilizemos o caso de uma mulher transexual, que biologicamente nasceu com a genitália masculina, mas sua expressão de gênero é feminina; sua fisionomia é feminina e ela se reconhece como tal, mas a utilização do nome masculino (que consta na sua documentação) pode gerar, e gera constrangimento quando é requisitado, assim, o nome social, que é escolhido por ela, facilita seu convívio em sociedade, e cessa o constrangimento da utilização do nome masculino que não corresponde com o seu ser.

Nesse sentido Mora, Lopes e Prandi (p.366, 2012) expõem que:

O nome social, em verdade, é a denominação construída por travestis e por transexuais para serem reconhecidos perante a sociedade e que possui relação direta com o gênero com o qual se identificam, seja ele masculino ou feminino. $\mathrm{O}$ termo
49

"reconhecidos" deve ser compreendido não apenas como a identificação do(a) travesti e do(a) transexual por terceiros interlocutores, mas também a forma como se compreendem e se reconhecem a si mesmos(as).

Nesse aspecto, o nome social é de suma importância para esse grupo de pessoas, acarretando um enquadramento entre nome e gênero, bem como um maior conforto psicológico na utilização dele.

Salienta-se que o pseudônimo dos artistas e escritores são protegidos pela legislação pátria, como consta no artigo 19 do código civil, no entanto, ainda existe uma relutância na utilização e proteção do nome social por parte do Estado, que em certos casos é omisso na tutela desse direito personalíssimo do ser humano.

\section{Utilização Do Nome Social Nas Escolas Do Estado Do Ceará}

O Estado brasileiro consagrou na Constituição Federal (art. $1^{\text {o }}$ ) o fundamento do pluralismo político, possibilitando assim, o livre desenvolvimento da personalidade do indivíduo, no qual este possui a liberdade 
de identificar-se com o gênero feminino, masculino, ou com nenhum destes, independentemente do seu sexo biológico. No entanto, o legislativo é moroso no sentido de debater e aprovar normas infraconstitucionais que garantam expressamente esta liberdade de desenvolvimento.

Essa mora do poder legislativo acarreta na necessidade dos indivíduos ingressarem com ações para que o judiciário se utilize da sua função atípica de legislar e possa regulamentar situações fáticas, como acontece em casos de inclusão de companheiro(a) homossexual em planos de saúde, requerimentos de cirurgias de readequação de sexo, entre outros. Nesse contexto, direitos e garantias da população LGBTTQIA são negados e até mesmo não apreciados, devido a morosidade do legislativo, sendo também consequência dos padrões e costumes heteronormativos.

O direito da utilização ao nome social já é reconhecido, no entanto, tem pouca aceitação social, principalmente devido aos padrões patriarcalistas inseridos na cultura brasileira. Necessário se faz adentrar com o debate nas escolas, e principalmente garantir as crianças e adolescentes o direito ao uso do nome social, manifestando uma correspondência entre o gênero e o nome utilizado.

O Brasil já teve avanços na proteção desse direito, e já possui normas que preveem a sua regulamentação. Nesse sentido explica Mora, Lopes e Prandi (p. 368, 2012):

É nesse contexto que alguns Estados da Federação regulamentaram a possibilidade de travestis e transexuais utilizarem no âmbito escolar o nome social ao invés do nome civil, como forma de inclusão, bem como efetivação do princípio da igualdade de condições para acesso e permanência na escola, nos estritos termos do art. 206, inciso I, da Constituição Federal.

\section{O Conselho Estadual de}

Educação do Estado do Ceará publicou a Resolução No 437/2012 que aborda a temática inclusão do nome social de travestis e transexuais nos registros escolares do sistema Estadual de ensino. Essa resolução é um avanço, mas não é suficiente, continuando a carência de regulamentação pelo poder legislativo.

$\mathrm{O}$ artigo $1^{\circ}$ da referida resolução dispõe que:

Art $1^{\circ}$ Determinar, quando requerido, que as instituições escolares de educação básica 
e de ensino superior, vinculadas ao Sistema Estadual de Educação do estado do Ceará, em respeito à cidadania, aos direitos humanos, à diversidade, ao pluralismo, à dignidade da pessoa humana; além do nome civil, incluam o nome social de travestis e transexuais em todos os registros internos dessas instituições.

O nome social é uma forma de inclusão nas escolas, devendo ser respeitado e resguardado. Nesse sentido, o poder executivo tem se manifestado na tutela desse direito, como verificado na resolução supramencionada. $\mathrm{O}(\mathrm{a})$ Transexual e a travesti já se expõem no ambiente escolar simplesmente por assumirem a sua condição, estando expostos a olhares que já os classificam como diferentes. Sendo também, submetidos a situações constrangedoras e vexatórias sempre que são identificados pelo seu nome civil, e têm a sua intimidade exposta, pois são obrigados a explicar o porquê do nome civil não corresponder a sua expressão de gênero.

Essa falta de inclusão, conjuntamente somado a sensação de não pertencer ao meio, acarreta a desistência escolar, e por consequência, a falta de capacitação educacional/profissional dos transgêneros. Nesse sentido explica Mora, Lopes e Prandi (p. 369-370, 2012): "uma pessoa que se sente excluída e com seus direitos desrespeitados não tem motivação para permanecer em um local onde a discriminação e o preconceito prevalece".

A resolução 437/2012 prevê nos parágrafos $1^{\circ}$ e $2^{\circ}$ do artigo $1^{\circ}$, a idade para requerer a utilização do nome social nos registros das instituições escolares:

$\S 1^{\circ} \mathrm{O}$ estudante maior de 18 (dezoito) anos poderá manifestar o desejo, por escrito, de inclusão do seu nome social pela instituição educacional no ato da matrícula ou, a qualquer momento, no decorrer do ano letivo.

$\S 2^{\circ}$ Para os estudantes que não atingiram a maioridade legal, a inclusão poderá ser feita mediante autorização conjunta, por escrito, dos pais ou responsáveis, ou por decisão judicial.

Dessa forma, os estudantes a partir dos 18 anos podem expressar a sua vontade de utilização do nome social, e os estudantes que ainda não completaram essa idade, poderão fazê-lo 
mediante autorização conjunta dos pais ou representantes legais, bem como por decisão do judiciário.

A resolução $\mathrm{N}^{\mathrm{o}} 12$, de 16 de janeiro de 2015 da Presidência do Conselho Nacional de Combate à Discriminação e Promoção dos Direitos de Lésbicas, Gays, Travestis e Transexuais, corrobora o entendimento da utilização do nome social no ambiente escolar, e nos seus artigos $1^{\circ}$ e $2^{\circ}$ dispõem:

Art. $1^{\circ}$ Deve ser garantido pelas instituições e redes de ensino, em todos os níveis e modalidades, 0 reconhecimento e adoção do nome social àqueles $\mathrm{e}$ àquelas cuja identificação civil não reflita adequadamente sua identidade de gênero, mediante solicitação do próprio interessado.

Art. $2^{\circ}$ Deve ser garantido, àquelas $\mathrm{e}$ àqueles que $\mathrm{o}$ solicitarem, o direito ao tratamento oral exclusivamente pelo nome social, em qualquer circunstância, não cabendo qualquer tipo de objeção de consciência.

Essa resolução, juntamente com a resolução 437/2012, fundamentam e garantem a utilização do nome social no ambiente escolar, bem como no artigo $2^{\circ}$ da resolução $12 / 2015$, garante o direito ao tratamento oral exclusivamente pelo nome social.

Dessa forma, além de constar nos registros internos das escolas o campo para preenchimento do nome social dos alunos transexuais e travestis, também deverá haver o tratamento oral por tal nome, por parte dos funcionários das entidades escolares, e por consequência, pelos demais alunos.

\section{Conclusão}

A utilização do nome social é garantido as travestis e as/os transexuais no Estado do Ceará por duas resolução que tratam da temática. No entanto, o poder legislativo ainda se encontra inerte e moroso no sentido de regulamentar tal situação e promulgar leis para efetivar os direitos dessa parcela da sociedade.

A comunidade LGBTTQIA enfrenta diariamente barreiras para garantir seus direitos, bem como na efetivação dos mesmos. Ocorre que existe a norma que garante o uso do nome social, mas por muitas vezes essa norma não possui eficácia, e essa população deixa de usufruir de garantias previstas em normas por causa de negligência de algum dos três poderes (legislativo, executivo ou judiciário).

O nome social é um direito 
previsto e regulamentado, devendo ser utilizado no ambiente escolar, no qual as travestis e as/os transexuais podem requerer a inclusão dele nos seus registros internos, bem como é garantido o tratamento oral exclusivamente pelo nome social.

\section{Referências}

BARBOSA, Bruno César. Nomes e Diferenças: uma etnografia dos usos das categorias travesti e transexual. 2010. Tese de Doutorado. Universidade de São Paulo.

BRASIL. Tribunal Regional Federal

(4. Região). Apelação Cível no 26279RS (2001.71.00.026279-9). Disponível em: $\quad<\underline{\text { https://trf- }}$ 4.jusbrasil.com.br/jurisprudencia/86507 19/apelacao-civel-ac-26279-rs20017100026279-9/inteiro-teor-

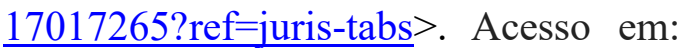
22 de jun. de 2018.

BUTLER, Judith P. Problemas de gênero: feminismo e subversão da identidade. Rio de Janeiro: Civilização Brasileira, 2003.

BRASIL. Constituição da República Federativa do Brasil de 1988. Disponível em:
$<$ http://www.planalto.gov.br/ccivil 03/c onstituicao/constituicao.htm>. Acesso em: 14 de maio de 2018.

CONSELHO NACIONAL DE COMBATE À DISCRIMINAÇÃO E PROMOÇÕES DOS DIREITOS DE LÉSBICAS, GAYS, TRAVESTIS E TRANSEXUAIS- CNCD/LGBT. Estabelece parâmetros para garantia das condições de acesso e permanência de pessoas travestis e transexuais - e todas aquelas que tenham sua identidade de gênero não reconhecida em diferentes espaços sociais - nos sistemas $\mathrm{e}$ instituições de ensino, formulando orientações quanto ao reconhecimento institucional da identidade de gênero e sua operacionalização. Resolução $\mathrm{N}^{\mathrm{o}} 12$, de 16 de janeiro de 2015

MORA, Edinei Aparecido; LOPES, Fernando Augusto Montai y; PRANDI, Luiz Roberto. A utilização do nome social por travestis e transexuais na rede de ensino como forma de inclusão social. In: VIEIRA, Tereza Rodrigues. (org.). Minorias Sexuais. Brasília: Consulex, 2012, p.353-374.

Próchno, C. C. S. C. \& Rocha, R. M. G. (2011). O jogo do nome nas subjetividades travestis. Psicologia \& Sociedade, 23(2), 254-261.

SCOTT, J. W. Gênero: uma categoria útil para analise histórica. New York, Columbia University Press. 1989. 